\title{
NUEVA NORMATIVA LEGAL APLICADA A LOS ESTADOS FINANCIEROS ELEVA LA RESPONSABILIDAD DEL CONTADOR PÚBLICO
}

\author{
NEW LEGAL REGULATIONS APPLIED TO FINANCIAL STATEMENTS \\ INCREASES THE RESPONSIBILITY PUBLIC ACCOUNTANT
}

\section{Ernesto A. Polar Falcón *}

Docente Principal de la Facultad de Ciencias Contables, UNMSM

[Recepción: Agosto de 2011 / Conformidad: Octubre de 2011]

\section{RESUMEN}

En el texto de la Ley No. 29720 - "Ley que promueve las emisiones de valores mobiliarios y fortalece el mercado de capitales", el Artículo 5 indica que sociedades y entidades distintas a las que se encuentran bajo la supervisión de Conasev, deben presentar Estados Financieros Auditados a partir del año 2011, preparados por sociedades de auditoría habilitadas por un colegio de contadores públicos del Perú, cuando los ingresos anuales por venta de bienes o prestación de servicios o sus activos totales sean iguales o excedan a tres mil unidades impositivas (UIT).

En el presente artículo se precisa la importancia que tiene esta normativa legal, que permite el incremento de los servicios profesionales de auditoría; y se promueve mayor interés en la preparación de los Estados Financieros, elevándose la responsabilidad del Contador Público. Se analizan varias normas legales, societarias y tributarias, identificadas con la información contable solicitada; así como los resultados de las investigaciones efectuadas a nivel del Colegio de Contadores Públicos de Lima y de las Facultades que tienen la responsabilidad en la formación del Contador Público.

Palabras Clave: Estados Financieros, Normativa Contable, Ética Profesional, Normativa Legal.

\section{ABSTRAC}

In the text of Law No. 29720 - "An Act to promote securities emissions and strengthens the capital market", Article 5 states that companies and entities other than those that are under the supervision of Conasev, States must submit financial Statements from the year 2011, prepared by audit firms authorized by a school of public accountants of Peru, where the annual income from the sale of goods or services or total assets equal or exceed three thousand tax units (UIT) .

This Article specifies the importance of such legislation, which allows the increase of professional auditing services, and promotes greater interest in the preparation of financial statements, raising the responsibility of the practitioner. We analyze various legislation, corporate and tax, identified by the accounting information requested, and the results of investigations conducted at the Institute of Chartered Accountants of Lima and the Schools that have the responsibility for the formation of a public accountant.

Keywords: Financial Statements, Accounting Standards, Ethics, Legal Regulations.

* Doctor en Educación, Magíster en Educación, Contador Público Colegiado Certificado. Docente Principal de la Facultad de Ciencias Contables de la UNMSM. 


\section{INTRODUCCIÓN}

El 25 de Junio del 2011 se publicó la Ley No. 29720 "Ley que promueve las emisiones de valores mobiliarios y fortalece el mercado de capitales". En el texto de esta Ley, se lee el siguiente artículo:

"Artículo 5. Publicidad de información financiera de empresas no supervisadas

Las sociedades y entidades distintas a las que se encuentran bajo la supervisión de Conasev, cuyos ingresos anuales por venta de bienes o prestación de servicios o sus activos totales son iguales o excedan a tres mil unidades impositivas tributarias (UIT), deben presentar a dicha entidad sus estados financieros auditados por sociedades de auditoría habilitadas por un colegio de contadores públicos del Perú, conforme a las normas internacionales de información financiera y sujetándose a las disposiciones y plazos que determine Conasev. La unidad impositiva tributaria (UIT) de referencia es la vigente el 1 de Enero de cada ejercicio.

Los estados financieros presentados son de acceso al público.

En caso de que Conasev detecte que alguna de las sociedades o entidades a que se refiere el presente artículo no cumplen con la obligación de presentar los referidos estados financieros anuales, puede, con criterio de razonabilidad y proporcionalidad, imponerle la sanción administrativa de amonestación o multa no menor de una ni mayor de veinticinco unidades impositivas tributarias (UIT)"

Al respecto la Cámara de Comercio de Lima indica: "que lesiona la reserva de información contable, pues se pretende dar publicidad a la información de las sociedades y ello contrariamente al fin perseguido, facilitaría las maniobras especulativas, generando distorsiones en el mercado y solicita al Congreso de la República la derogatoria del Artículo 5 de la Ley No. 29720, a fin de mantener el carácter voluntario de los estados financieros y que sólo las sociedades anónimas abiertas (cuyo ámbito involucra dinero de terceros) estén obligados a auditar sus estados financieros - Ley General de Sociedades - Código de Comercio - son suficientes para garantizar la idoneidad de los estados financieros, porque establecen que éstos deben elaborarse con arreglo a los principios de contabilidad generalmente aceptados".

La reacción del Colegio de Contadores Públicos de Lima, ha sido positiva, por cuanto se ha preocupado en organizar cursos de Auditoría Financiera, dirigido a Contadores Públicos con el apoyo de las Sociedades de Auditoría vigentes, que han ofrecido como docentes a sus experimentados profesionales en Auditoría, sin costo alguno.

Frente a este panorama, el presente artículo considera que la profesión contable en el Perú, está recibiendo una importante responsabilidad, tanto a nivel de Contadores Públicos en sus funciones como Contadores Generales de empresas, responsables de preparar Estados Financieros; como a nivel de Contadores Públicos responsables de desarrollar una Auditoría Financiera sobre los Estados Financieros, ya sea como miembros de Sociedades de Auditoría o como Auditores Independientes. Esta responsabilidad indudablemente elevará el prestigio de la profesión del Contador Público en el Perú y debe considerarse como una actividad más en el permanente proceso de la Educación Profesional Continua del Contador Público que se define como la actividad educativa programada, formal y reconocida en la profesión, con el objeto de actualizar y mantener conocimientos profesionales en el nivel que exige su responsabilidad social; por cuanto está obligado el Contador Público a suministrar datos de mejor calidad, oportunos, comprensibles, y lo más importante transparentes.

Las universidades públicas y privadas de Lima Metropolitana, no se han pronunciado sobre esta nueva norma, vigente para el año 2011 en adelante, esperando seguramente mayores aclaraciones en el Reglamento de dicha Ley o Conasev determine nuevas "disposiciones y plazos" según se lee en el primer párrafo del Artículo 5.

Sin embargo, las Facultades de universidades públicas o privadas, que tienen la responsabilidad en la formación del Contador Público, deberán revisar sus sílabos de enseñanza de los cursos de Auditoría y constatar que efectivamente los egresados estén debidamente preparados para 
preparar Estados Financieros de acuerdo con la normatividad vigente, especialmente la proveniente de la aplicación correcta de las Normas Internaciones de Contabilidad (NIC's); de las Normas Internacionales de Información Financiera (NIIF's) emitidas por el Consejo de Normas Internaciones de Contabilidad (IASB) e Interpretaciones; y de las Normas Internacionales de Auditoría (NIA)

De igual forma, deberán conocer el contenido del Reglamento de Información Financiera, que consta de nueve (9) capítulos y el Manual para la Preparación de la Información Financiera, que forma parte del mencionado Reglamento con cinco (5) secciones.

En el libro "Plan Contable General Empresarial" de Ediciones Caballero Bustamante, del cual el investigador de este artículo es "coautor", se indica lo siguiente:

"Por mandato del artículo $223^{\circ}$ de la Ley General de Sociedades, en adelante la LGS (Ley No. 26887, vigente a partir del 1 de enero de 1998) se establece que "Los estados financieros (1) se preparan y presentan de conformidad con las disposiciones legales sobre la materia y con principios de contabilidad generalmente aceptados".

$\mathrm{Al}$ respecto, cabe señalar que tratándose de sociedades en general (no sujetas a regulación especial (2) tales disposiciones y principios son los siguientes:

- $\quad$ El artículo $221^{\circ}$, primer párrafo, según el cual los estados financieros deben reflejar "con claridad y precisión" la situación económica y financiera de la sociedad y los resultados obtenidos en el ejercicio vencido.

Las resoluciones que expide el Consejo Normativo de Contabilidad al amparo del artículo $14^{\circ}$ de la Ley No. 28707 (publicada el 12.04.2006), como órgano del Sistema Nacional de Contabilidad creado por dicha ley, encargado de la emisión de normas que deben regir la contabilidad en el país para el sector privado.

Las Normas Internaciones de Contabilidad (NIC's) y las Normas Internacionales de Información Financiera (NIIF's) emitidas por el Consejo de Normas Internacionales de Contabilidad - IASB (antes Comité de Normas Internacionales de Contabilidad - IASC), cuya aplicación a nivel nacional haya sido oficializada y no haya sido dejada sin efecto por Consejo Normativo de Contabilidad; y, por excepción, tratándose de procedimientos operativos contables que no estén normados por las NIIFs, los Principios de Contabilidad aplicados en los Estados Unidos de Norteamérica (USGAAP). Así lo han dispuesto los artículos $1^{\circ}$ y $2^{\circ}$ de la Resolución del Consejo Normativo de Contabilidad No 013-98-EF/93.01

1) De acuerdo a la Cuarta Disposición Final de la LGS se entiende por Estados Financieros al Balance General y Estado de Ganancias y Pérdidas. No obstante ello, téngase en cuenta que la NIC 1 considera como Estados Financieros, también al Estado de Flujos de Efectivo, así como el Estado de Cambios en el Patrimonio Neto, además de las Notas a los Estados Financieros.

2) Es el caso de las empresas sujetas a la supervisión de la Comisión Nacional Supervisora de Empresas y Valores (CONASEV), en las cuales se incluye ahora las empresas no supervisadas de acuerdo al Artículo 5 de la Ley No 29720"

3) Como complemento del presente artículo, es importante mostrar la Norma Internacional de Contabilidad (NIC1) - "Presentación de Estados Financieros" en las tres siguientes áreas de sus artículos:

\section{OBJETIVO}

1) El objetivo de esta Norma consiste en establecer las bases para la presentación de los estados financieros con propósitos de información general, a fin de asegurar que los mismos sean comparables, tanto con los estados financieros de la misma entidad de ejercicios anteriores, como con los de otras entidades diferentes. 
Para alcanzar dicho objetivo, la Norma establece, en primer lugar, requisitos generales para la presentación de los estados financieros y, a continuación, ofrece directrices para determinar su estructura, a la vez que fija los requisitos mínimos sobre su contenido. Tanto el reconocimiento, como la valorización a revelar sobre determinadas transacciones y otros eventos, se abordan en otras Normas e Interpretaciones.

\section{ALCANCE}

a) Esta Norma se aplicará a todo tipo de estados financieros con propósitos de información general, que sean elaborados y presentados conforme a las Normas Internacionales de Información Financiera (NIIF)

\section{COMPONENTES DE LOS ESTADOS FI- NANCIEROS}

2) Un conjunto completo de estados financieros incluirá los siguientes componentes:

a) Balance general;

b) Estado de ganancias y pérdidas;

c) Un estado de cambios en el patrimonio neto que muestre:

- Todos los cambios habidos en el patrimonio neto; o bien

- Los cambios en el patrimonio neto dis tintos de los procedentes de las transac ciones con los propietarios del mismo, cuando actúen como tales;

d) Estado de flujos de efectivo; y

e) Notas, en las que incluirá un resumen de las políticas contables más significativas y otras notas explicativas.

A la presentación de estos antecedentes, el Objetivo General de este artículo se define en los siguientes términos:
"Determinar la importancia de la nueva normativa legal aplicada a los Estados Financieros que eleva la responsabilidad del Contador Público en el Perú"

El presente artículo tiene justificación práctica, por cuanto su desarrollo ayuda a resolver el problema, al despertar el interés en dar mayor importancia a esta nueva normativa legal proponiendo ciertas estrategias de estudios sobre los Estados Financieros, a nivel profesional y universitario, que al aplicarse adecuadamente contribuirán a aumentar el mayor interés sobre este tema.

La limitación del estudio del problema, se enmarcan en una limitación de tiempo, ya que se está determinando que en un período de aplicaciones de las sugerencias dadas, deben aplicarse en forma rápida, considerando que al cierre del ejercicio 2011, se tiene que cumplir con la presentación de Estados Financieros Auditados, en una considerable cantidad de empresas, que al cierre del indicado año, sus ventas de bienes serán iguales o excederán a tres mil unidades impositivas tributarias (UIT)

\section{RESULTADOS OBTENIDOS}

Una primera tarea de recolección de información, ha sido revisar una muestra de ejemplares de Estados Financieros Auditados 2010, de trabajos profesionales realizados en el primer semestre del año 2011. Sobre el particular, se han revisado Estados Financieros Auditados 2010 emitidos por Sociedades de Auditoría que tienen representación internacional.

$\mathrm{Al}$ respecto, es oportuno mostrar algunas de las siguientes áreas expuestas en el Estudio de Investigación 2009, titulado "La Ética y su Aporte a la Calidad que aplica el Contador Público en el Perú", como:

"La Ética y su Aporte a la Calidad, son temas fundamentales que debe conocer el Contador Público y aplicar en su trabajo 
Profesional. Sin embargo, tanto a nivel interamericano como nacional, se observa consumapreocupación que se sigue teniendo problemas en su aplicación que afectan la imagen profesional"

En "Valores y Responsabilidad Social" se indica lo siguiente:

"El Contador Público "debe actuar", con responsabilidad social, pues la calidad del servicio y de las relaciones que pueden darse entre el profesional y el usuario son únicas.

Tenemos la convicción que más allá de la existencia de normas, es fundamental el rol de las universidades, en la formación de profesionales, tanto en temas técnicos, como el desempeño de ciudadanos responsables que trabajen por un mundo mejor.

Es por ello que recomendamos "la formación en valores" del profesional en las Ciencias Contables como responsabilidad inaplazable para contribuir a la excelencia profesional"

Y se recuerda la aplicación del "Programa de Control de Calidad", proponiendo los siguientes puntos:

"El Programa de Control de Calidad debe permitir certificar el Contador Público:

- Cumpla con la obligación profesional de establecer y mantener normas de calidad en el trabajo que realiza.

Promueva la calidad y eficiencia en la ejecución de los trabajos en conformidad con normas profesionales.

- El comportamiento integro y ético de su personal

- La participación en el adiestramiento que fomenten la preparación técnica y las cualidades profesionales, éticas y morales del personal.

Así como, el "Programa de Revisión", que también propone tres objetivos:

El Programa de Revisión entre Contadores Públicos es utilizado para evaluar y certificar a tra- vés de una revisión los trabajos que realizan los Contadores Públicos y las firmas de contabilidad. Incluye un estudio de la idoneidad de las políticas del control de calidad y de las pruebas que determinan el cumplimiento con ellas:

1) Base razonable para expresar una opinión sobre si ha demostrado la competencia necesaria para realizar los trabajos de contabilidad y auditoría.

2) Determinar si el sistema de control de calidad que ha diseñado están de acuerdo a los elementos de control de calidad.

3) Evaluar si el sistema provee una certeza razonable en cuanto al cumplimiento con las normas profesionales y los requisitos legales.

Asimismo, se ha observado que algunos Contadores Públicos que recién están acumulando experiencia y que ejercen la delicada tarea de Contadores Generales en empresas del sector privado, presentan a Gerencia, solamente el Balance General y Estado de Ganancias y Pérdidas, como resultados finales de la gestión operativa de un año; dejando la tarea de preparar los Estados Financieros a los Auditores Externos.

La estructura de los Estados Financieros, está normada por el Manual para la Preparación de Información Financiera, bajo el siguiente Índice

\section{NORMAS CONTABLES OFICIALIZADAS EN EL PERÚ}

Las últimas Normas Internacionales de Contabilidad - (NIC), de la 1 a la 41, fueron emitidas por el Comité de Normas Internacionales de Contabilidad (IASC por sus siglas en inglés), y las interpretaciones 1 al 33, emitidas por el Comité Permanente de Interpretaciones (SIC), oficializadas por el Consejo Normativo de Contabilidad (CNC) para su aplicación en el Perú. 


\begin{tabular}{|c|c|c|}
\hline$\underline{\text { Sección }}$ & Título & Capítulo \\
\hline \multirow[t]{4}{*}{ PRIMERA } & Los Estados Financieros & I. Balance General \\
\hline & & II. Estado de Ganancias y Pérdidas \\
\hline & & III. Estado de Cambios en Patrimonio \\
\hline & & IV. Estado de Flujos de Efectivo \\
\hline \multirow[t]{2}{*}{ SEGUNDA } & Nota a los Estados Financieros & I. $\quad$ Notas de Carácter General \\
\hline & & II. Notas de Carácter Específico \\
\hline TERCERA & Informe de Gerencia & \\
\hline CUARTA & Información Financiera Auditada & \\
\hline \multirow[t]{2}{*}{ QUINTA } & $\begin{array}{l}\text { Modelo a utilizarse en la presentación de los } \\
\text { Estados Financieros }\end{array}$ & \\
\hline & Glosario & \\
\hline
\end{tabular}

En las Notas a los Estados Financieros, es importante agregar las siguientes notas de actualidad contable y tributaria, como información relacionada con el ejercicio 2011:

El Consejo Normativo de Contabilidad (CNC) mediante Resolución No. 034-2005EF/93.01 del 17 de febrero de 2005, publicada el 2 de marzo de 2005, aprobó oficializar las Normas Internacionales de Información Financiera (NIIF) 1 a la 5, y las nuevas versiones de las Normas Internacionales de Contabilidad (NIC) que habían sido modificadas por el Consejo de Normas Internacionales de Contabilidad, (IASB por sus siglas en inglés) en diciembre de 2003 y en marzo de 2004, y dejar sin efecto a partir del $1^{\circ}$ de enero de 2005 la NIC 15, y a partir del $1^{\circ}$ de enero de 2006 las NIC 22 y 35, y la mayoría de la Interpretaciones emitidas por el SIC.

Posteriormente, según Resolución No. 036-2005-EF/93.01 del 18 de noviembre de 2005, publicada el 15 de diciembre de 2005, la CNC aprobó oficializar la NIIF 6, Exploración y Evaluación de Recursos Minerales.

De acuerdo a lo establecido por las referidas Resoluciones, las NIIF y las nuevas versiones de las NIC antes mencionadas, son aplicables en la preparación y presentación de estados financieros que correspondan a períodos que se iniciaron el $1^{\circ}$ de enero de 2006.

Asimismo, el CNC mediante Resolución no. 038-2005-EF/93.01, del 28 de diciembre de 205, publicada el 3 de febrero de 2006, acordó:

a) Suspender hasta el 31 de diciembre de 2006 la aplicación obligatoria en el país de la NIC 21 - Efectos de las Variaciones en los Tipos de Cambio de Monedas Extranjeras, modificada en diciembre de 2003, y restituir por el mismo período la aplicación de la NIC 21 revisada en 1993 y sus correspondientes Interpretaciones $19 \mathrm{y}$ 30 , excepto el tratamiento alternativo señalado en los párrafos 20,21 y 22 de la citada NIC, que permitían incluir los ajustes por diferencia de cambio en el valor contable de un activo.

b) Mantener la aplicación en el Perú del Método de Participación Patrimonial para la valuación de las inversiones en subsidiarias, entidades conjuntamente controladas $\mathrm{y}$ asociadas; que se presenten en estados 
financieros individuales, como un método adicional a los establecidos por las NIC 27 y 28 modificadas en diciembre de 2003

Las NIC's 21, 27 y 28, modificadas en 2003, habían sido oficializadas por CNC para su aplicación obligatoria en Perú a partir del $1^{\circ}$ de enero de 2006, y optativamente a partir del $1^{\circ}$ de enero de 2005 , mediante Resolución No. 034-2005-EF/93.01 del 17 de febrero de 2005, publicada el 2 de marzo de 2005.

La indicada Resolución no impide la aplicación optativa de la NIC 21 - modificada en diciembre de 2003, en los términos señalados en Resolución No. 034-2005-EF/93.01.

El Consejo Normativo de Contabilidad (CNC) mediante Resolución 044-2010EF/94, oficializó las Normas Internaciones de Contabilidad (NIC) 1 al 41, las Normas Internacionales de Contabilidad (NIC) 1 al 41, las Normas Internaciones de Información Financiera (NIIF) 1 a 8, las interpretaciones SIC 7 a 32 y CINIIF 1 a 19 que son vigentes a partir del $1^{\circ}$ de enero de 2011.

\section{PLAN CONTABLE GENERAL EMPRESARIAL}

Con Resolución No. 043-2010-EF/94 del Consejo Normativo de Contabilidad, se aprobó la versión modificada del Plan Contable General Empresarial (PCGE) cuya aplicación obligatoria rige a partir del ejercicio 2011.

El PCGE tiene como objetivos:

a) La acumulación de la información sobre los hechos económicos que una empresa debe registrar según las actividades que realiza, de acuerdo con una estructura de códigos que cumpla con el modelo contable oficial en el Perú, que es el que corresponde a las Normas Internacionales de Información Financiera (NIIF) b) Proporcionar a las empresas los códigos contables para el registro de sus transacciones, que les permitan, tener un grado de análisis adecuado; y con base en ello, Estados Financieros que reflejen su situación financiera, resultados de operaciones y flujo de efectivo.

c) Proporcionar a los organismos supervisores y de control, información estandarizada de las transacciones que las empresas efectúan.

No obstante que este PCGE ha sido diseñado para empresas, es decir, para actividades que persiguen fines de lucro, de cualquier tamaño o sector económico, su contenido, con cambios reducidos, puede ser adaptado a otras entidades.

\section{MODIFICACIONES APLICABLES EN LOS EJERCICIOS 2011 Y SIGUIENTES}

\section{Libros y Registros Contables vinculados a asuntos tributarios}

La Resolución de Superintendencia No. 017-2009/SUNAT ha establecido la implementación de determinados libros y registros contables electrónicos vinculados a asuntos tributarios, en consecuencia, desde julio de 2010 los contribuyentes deberán llevar sus libros y registros contables vinculados con asuntos tributarios, considerando los formatos y requisitos mínimos.

Modificaciones al Impuesto a la Renta vigentes a partir del ejercicio 2011.

La Ley No. 29645 publicada el 31 de diciembre de 2010 ha establecido las siguientes modificaciones:

- Renta Exonerada por intereses provenientes de crédito de fomento y ganancias de capital por enajenación de valores mobiliarios.

La ley ha definido el concepto de intereses provenientes de créditos de fomento esta- 
bleciéndolo como aquellas operaciones de endeudamiento que se destinen a financiar proyectos y programas para el desarrollo del país en obras públicas de infraestructura, prestación de servicios públicos y otros indicados en la Ley

- Deducción de gastos comunes a rentas de distinta naturaleza.

Se ha incorporado al artículo $51^{\circ}-$ A del TUO de la Ley de Impuesto a Renta, la norma aplicable a las personas naturales, sucesiones indivisas y sociedades conyugales domiciliadas en el país, para regular gastos cuando éstos incidan conjuntamente en rentas de fuente extranjera provenientes de la enajenación de acciones y otros valores y las demás rentas de fuente extranjera, estableciendo que la deducción se hará en forma proporcional de acuerdo a lo que establezca el Reglamento.

- Tasas del Impuesto a la Renta aplicable a Personas No Domiciliadas establecidas en el artículo $54^{\circ}$ y $56^{\circ}$ de la Ley de Impuesto a la Renta.

Se reduce la tasa del 30\% al $4.99 \%$ aplicable a personas naturales no domiciliadas por concepto de intereses, siempre que quien pague los intereses o los acredite sea un generador de renta de tercera categoría domiciliado en el país, no vinculado al receptor de la renta y que no provenga de operaciones realizadas desde paraísos fiscales.

\section{Ley 29646 - Ley de Fomento al Comercio Exterior de Servicios}

La Ley 29646 publicada el $1^{\circ}$ de enero de 2011, ha establecido el marco normativo para el fomento del comercio exterior de los servicios.

La Ley define a la exportación de servicios como el suministro de un servicio de cualquier sector, a través de las modalidades de comercio fronterizo, consumo extranjero, presencia comercial y presencia de personas físicas.

\section{Exoneración del Impuesto a la Renta.}

Las exoneraciones establecidas en el artículo $19^{\circ}$ del TUO de la Ley del Impuesto a Renta estarán vigentes hasta el 31 de diciembre de 2011.

\section{Impuesto General a las Ventas}

La Ley 29666 publicada el 20 de febrero de 2011, ha restituido a partir del $1^{\circ}$ de marzo de 2011 la tasa del 16\% del Impuesto a las Ventas. Para tal efecto, la referida ley ha derogado el artículo 7o de la Ley 29628, Ley de Equilibrio Financiero del Presupuesto del Sector Público para el año fiscal 2011, artículo que precisamente prorrogó el porcentaje del IGV en u $17 \%$ hasta el 31 de diciembre de 2011.

La tasa que aplicará a partir del $1^{\circ}$ de marzo de 2011 será del $18 \%$, en vista que a la tasa del IGV (16\%) deberá agregársele el $2 \%$ por el Impuesto de Promoción Municipal (2\%).

\section{CONCLUSIONES}

1. La importancia que le ha dado la profesión contable en el Perú, a la nueva normativa legal aplicada a los Estados Financieros, ha sido limitada. La única acción publicada corresponde a la organización de cursos de Auditoría Financiera, dictadas en el Colegio de Contadores Públicos de Lima, a cargo de experimentados profesionales de la Auditoría, sin costo alguno. No se conoce acciones para incrementar la actividad del permanente proceso de Educación Profesional Continua del Contador Público.

2. Las Facultades de universidades públicas o privadas, que tienen la responsabilidad de la formación de futuros Contadores Públicos, no han efectuado publicacio- 
nes de cursos o seminarios dirigidos a bachilleres y egresados, relacionados con reforzar los procesos de preparación de Estados Financieros.

3. En la universidad designada como muestra, no se ha observado acciones académicas adicionales a los cursos de Estados Financieros, en las áreas de Contabilidad y Auditoría, con la finalidad de incentivar a mayores estudios del tema.

\section{REFERENCIAS BIBLIOGRÁFICAS}

1. Bernal César A. (2006) - Metodología de la Investigación - Pearson Educación, México

2. Polar F. Ernesto (2009) - Plan Contable General Empresarial - Ediciones Caballero Bustamante, Lima

3. Polar F. Ernesto (2009) - La Ética y su Aporte a la Calidad - Revista Quipukamayoc - Instituto de Ciencias Financieras y Contables - Facultad de Ciencias Contables - UNMSM
4. Ley No. 26887 - Ley General de Sociedades

5. Ley No. 29666 - Restitución de la Tasa del 16\% del IGV

6. Ley No. 29645 - Modificaciones al Impuesto a la Renta

7. Ley No. 29720 - Ley que promueve las emisiones de Valores Mobiliarios y fortalece el Mercado de Valores - Art. 5 Publicidad de Información Financiera de Empresas no supervisadas

8. Federación Internacional de Contadores - IFAC

9. Resoluciones del Consejo Normativo de Contabilidad - CNC - Perú

10. Normas Internacionales de Contabilidad

11. Normas Internacionales de Información Financiera

12. Norma Internacional de Contabilidad No. 1 - Estados Financieros 